\title{
Effect of geopathic stress on human heart rate and blood pressure
}

\author{
N.P.Dharmadhikari ${ }^{1}$, A.P.Rao ${ }^{2}$, S.S.Pimplikar ${ }^{3}$,A.G.Kharat ${ }^{4}$, S.D.Aghav ${ }^{5}$, D.C.Meshram ${ }^{6}$,S.D.Kulkarni ${ }^{7}$ and B.B. Jain $^{8}$ \\ ${ }^{1}$ Dept. of Applied Physics; ${ }^{2}$ Dept. of Electronic \&Telecommunication, JSPM'S Jayawantrao Sawant College of Eng., \\ Hadapsar, Pune-28, India; ${ }^{3}$ Dept. of Civil Eng., Maharashtra Institute of Technology, Kothrud, Pune-38, India. \\ ${ }^{4}$ Dept. of Civil Eng., Sinhgad Academy of Eng., Kondhwa (Bk.) Pune-48, India. \\ ${ }^{5}$ Dept. of Physics, Baburaoji Gholap College, Sangavi, Pune-27, India \\ ${ }^{6}$ Dept. of Geology, University of Pune, Pune-7, India. \\ ${ }^{7}$ Dept. of Environmental Science, New Arts Commerce \& Sciences College Ahmednagar-414001, India. \\ ${ }^{8}$ Jayawantrao Sawant college of Pharmacy and Research, Hadapsar, Pune-28, India. \\ sejalrohit2007@gmail.com
}

\begin{abstract}
The energy emitted by the earth at a specific surface location which affects the normal human body function is termed as geopathic stress (GS). Empirical knowledge of the existence of geopathic stress is probably as old as mankind. However, scientific investigation about effect of GS on human system is an area of research. The aim of this work is to study the effect of geopathic stress on human system by recording blood pressure (BP), heart rate (HR). The observation indicates the change in blood pressure and heart rate in geopathic stress zones as compared to nonstress zones.
\end{abstract}

Keywords: Geopathic stress zone, blood pressure, heart rate.

Introduction

It can be very hard for the modern, well educated, pragmatic person to understand that there are disturbed vibrations coming out from the earth beneath, which can be harmful to human health. We have lived with the natural vibrations which rise up through the earth's mantle for millions of years. When these vibrations encounter subterranean running water, certain mineral concentration, fault lines and underground plateaux and cavities, their natural vibrations become disturbed and harmful to living organisms. In case of running water, normally $200-300 \mathrm{ft}$ (60-90 meters) underground, an electromagnetic field is created in opposite direction to its flow by friction which then creates strong unhealthy vibration. The effect of these higher vibrations has been called by many names such as black streams, cancer rays, negative green rays, Hartmann and Curry line and even ley lines. However, over the years now it is called Geopathic Stress (GS) (Gordon, 2005). The Chinese knew the harm Geopathic Stress (GS) could cause over 4000 years ago and avoided building houses on stressful places. Often people could be punished if the building was on what they called 'dragon line'. Extensive work has been published by various researchers to understand the effect of GS on the built environment (Kathe, 1989; Milliren, 1993; Pohl, 1993; Croome, 1994; Freshwater, 1997; Storozuk, 2002; Saunders, 2003; Thurnell-Read, 2006). Possible influences attributed to geopathic stress phenomena have been widely reported by the mass media, albeit without scientific proof. Apparently, geopathic stress does not only influence humans but all kind of animals, plants, fungi and bacteria (Hacker et al., 2005; Dubrov, 2008; Hacker et al., 2008). Dowsing, a valuable and low-cost way of detecting potential wells and circumventing effects of possible geopathy, e.g. in bed rooms, is being used all over the world. However, only few studies exist dealing with abilities of dowsers in a scientific way (Christopher Bird, 1993; Betz, 1995). The effects of GS on human system have not yet been proven by scientifically accepted techniques except a few (Dharmadhikari et al., 2009). The existence of the phenomenon has been known for a few thousand years, may be even since the early roots of mankind. Publications presenting scientific evidence of direct measurable effects of presumed GS on human system are very rare (Gridin et al., 2008). Heart rate is the main important health parameter of human body. Blood Pressure and heart rate depends on many factors like hormones, cations, age, gender, physical fitness, body temperature etc (Gadzicka, 1996; Jauchem, 1997; Derrickson, 2006). However, an attempt is made first time to study effect of GS on human body by measuring blood pressure [(Systole Pressure (SP), Diastole Pressure (DP), and Pulse rate (PR)], heart rate inside and outside geopathic stress zone.

\section{Experimental details}

With the help of expert dowser; using copper L-rod and Light Interference Technique many locations of geoapthic stress were identified on the Mumbai-Pune express-highway and residential area of Pune city. Only male candidates of various age groups were tested for changes in their blood pressure \& heart rate in GS and
Research article

CIndian Society for Education and Environment (iSee)
Geopathic stress on human heart rate http://www.indjst.org
Dharmadhikari et al. Indian J.Sci.Technol. 
Table 1. Observation table for measurement of SP, DP, PR and Heart Rate

\begin{tabular}{|c|c|c|c|c|c|c|c|c|c|}
\hline \multirow{2}{*}{$\begin{array}{l}\text { Age in } \\
\text { Year }\end{array}$} & \multirow{2}{*}{$\begin{array}{c}\text { Total } \\
\text { Candidate } \\
\text { studied }\end{array}$} & \multicolumn{2}{|c|}{$\begin{array}{c}\text { Average Systole } \\
\mathrm{BP}(\mathrm{mm} \text { of } \mathrm{Hg})\end{array}$} & \multicolumn{2}{|c|}{$\begin{array}{c}\text { Average Diastole } \\
\mathrm{BP}(\mathrm{mm} \text { of } \mathrm{Hg})\end{array}$} & \multicolumn{2}{|c|}{$\begin{array}{c}\text { Average Pulse } \\
\text { Rate }\end{array}$} & \multicolumn{2}{|c|}{$\begin{array}{c}\text { Average Heart } \\
\text { Rate (BPM) }\end{array}$} \\
\hline & & $\begin{array}{l}\text { Normal } \\
\text { Zone }\end{array}$ & $\begin{array}{c}\text { GS } \\
\text { Zone }\end{array}$ & $\begin{array}{l}\text { Normal } \\
\text { Zone }\end{array}$ & $\begin{array}{c}\text { GS } \\
\text { Zone }\end{array}$ & $\begin{array}{l}\text { Normal } \\
\text { Zone }\end{array}$ & $\begin{array}{c}\text { GS } \\
\text { Zone }\end{array}$ & $\begin{array}{l}\text { Normal } \\
\text { Zone }\end{array}$ & $\begin{array}{l}\text { GS } \\
\text { Zone }\end{array}$ \\
\hline 18 & 16 & 115.7 & 107.7 & 65.33 & 59 & 69 & 65.66 & 79.53 & 88.36 \\
\hline 20 & 25 & 115 & 124.3 & 71.66 & 75.66 & 71 & 76.66 & 69.4 & 62.27 \\
\hline 23 & 15 & 127.7 & 121 & 79 & 73 & 99 & 93.66 & 96.06 & 84.05 \\
\hline 24 & 10 & 124 & 124.7 & 74.33 & 79.66 & 76.33 & 79.33 & 78.46 & 76.94 \\
\hline 25 & 3 & 138.3 & 140.6 & 84 & 89.32 & 72 & 72.66 & 68.29 & 66.71 \\
\hline 26 & 9 & 120 & 113 & 59 & 54.33 & 67.33 & 67 & 79.5 & 72.33 \\
\hline 27 & 5 & 121.3 & 118.3 & 80.33 & 71 & 58 & 61 & 57.21 & 58 \\
\hline 28 & 6 & 120 & 99.33 & 70.66 & 61.33 & 54.33 & 57.66 & 55.15 & 57.46 \\
\hline 29 & 10 & 116.3 & 109.7 & 57.33 & 58.66 & 64.66 & 63 & 65.27 & 64.21 \\
\hline 30 & 11 & 126.7 & 132 & 76.66 & 86 & 66.66 & 74 & 77 & 72.38 \\
\hline 33 & 6 & 128.3 & 123.7 & 82.33 & 79.33 & 81.66 & 76.66 & 76.59 & 81.04 \\
\hline 35 & 9 & 117.3 & 114.7 & 76.66 & 67.66 & 91.33 & 86.33 & 76 & 85.3 \\
\hline 37 & 2 & 115.3 & 122.7 & 84.66 & 89.33 & 83.66 & 87.66 & 93.12 & 83.42 \\
\hline 38 & 5 & 114.3 & 122.3 & 83.66 & 88.23 & 96.66 & 98 & 95.3 & 97.64 \\
\hline 40 & 2 & 119.7 & 104.7 & 78.33 & 73 & 67.33 & 68 & 104.5 & 107.2 \\
\hline 42 & 3 & 117 & 113 & 72 & 79.66 & 71.66 & 59.66 & 78.15 & 76.08 \\
\hline 43 & 5 & 130.6 & 133 & 90.6 & 85.66 & 66.66 & 74.66 & 67.05 & 70.23 \\
\hline 46 & 7 & 118 & 120.7 & 78.66 & 82.66 & 79 & 84.66 & 81.16 & 82.8 \\
\hline 52 & 3 & 125.3 & 120.3 & 94 & 78.33 & 94 & 92.33 & 89.91 & 82.2 \\
\hline 54 & 2 & 121 & 127.5 & 85 & 79 & 85 & 78.5 & 85.6 & 81.3 \\
\hline
\end{tabular}

systolic \& diastolic blood pressure for GS zone varying in comparison with normal zone for different sample groups. To perform in depth study for determining the variation of blood pressure in geopathic stress zone and normal zone, a large number of people from different age groups are sampled to measure their blood pressure. Fig. 3 indicates the variation of blood pressure (SP \& DP both) with various age group people in normal \& pre-identified geopathic stress zone. The overall variation in non-GS location. The candidates were asked to rest in systole blood pressure and diastole blood pressure sleeping position for twenty minutes on the GS (Table 1).

Scientech ${ }^{(R)}$ digital blood pressure meter was used to record Systolic blood pressure (SP), Diastole Pressure (DP) and Pulse rate (PR) of candidates. BPL Cardio art 108T Digi ${ }^{(R)}$ make ECG machine was used to measure the human heart rate in bpm (beats per minutes). The jelly used was silver chloride which is specialized for ECG. The four limb electrodes were used for both hands and legs. One electrode was used for chest i.e. suction cup electrode.

Each heart beat produced a set of P-QRS-T waves which were recorded on rhythm strip (Fig.1). Heart rate is calculated using the formula

$$
H R=\frac{C S(\mathrm{~mm} / \mathrm{sec})}{R R(\text { int erval }) \mathrm{sec}} \times 60
$$

Fig. 1. The photograph for recording $P$-QRS-T waves of ECG

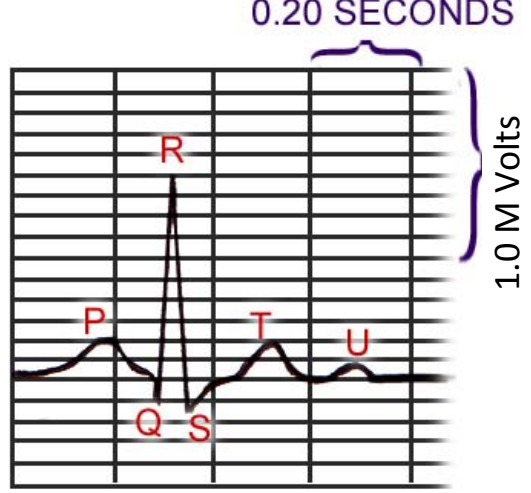

to be random. The micro analysis suggests notable decrease in systole blood pressure in the age group of 26 to 29 years and 40 to 48 years people. The diastole blood pressure is found to decrease in the age group of 26 to 28 years where as for the age group 38 to 42 years random fluctuations are noticed.

Fig.4 indicates that pulse rate of samples are both, greater as well as lesser in GS zone in comparison to normal zone. A more detailed study is carried out further for large number of samples to know the exact nature of pulse rate variation with age. Fig.5 depicts variation of pulse rate in normal \& pre-identified geopathic stress zone for people of different age group. There seems to be a zigzag variation in pulse rate in normal as well as pre-identified

$\mathrm{HR}=$ Heart Rate, $\mathrm{CS}=$ Chart speed, $\mathrm{RR}=\mathrm{RR}$ interval. Experimental observations are tabulated and related graph are plotted.

\section{Results and discussion}

Fig.2 indicates that the variation of blood pressure (systole, diastole pressure) for normal and pre-identified geopathic stress zone. The results indicate that both the

Research article

CIndian Society for Education and Environment (iSee)
Geopathic stress on human heart rate http://www.indjst.org
Fig. 2. Record of variation in systolic and diastolic $B P(\mathrm{~mm}$

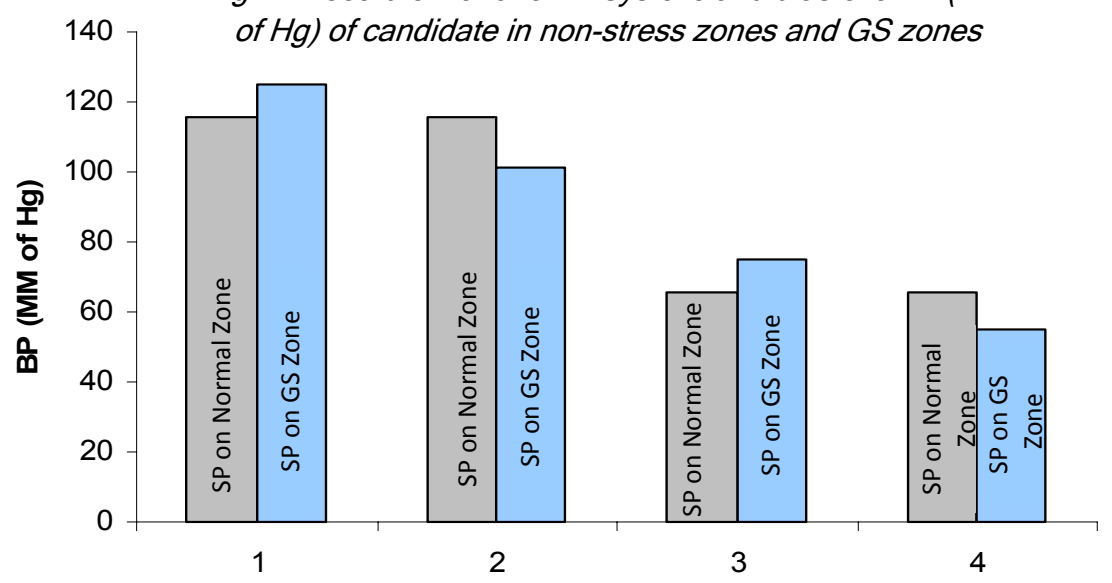

Dharmadhikari et al. Indian J.Sci.Technol. 
Fig. 3. Record of variation in systolic and diastolic BP $(\mathrm{mm}$ of $\mathrm{Hg}$ ) of candidate in non-stress zones and GS zones vs. age of candidate

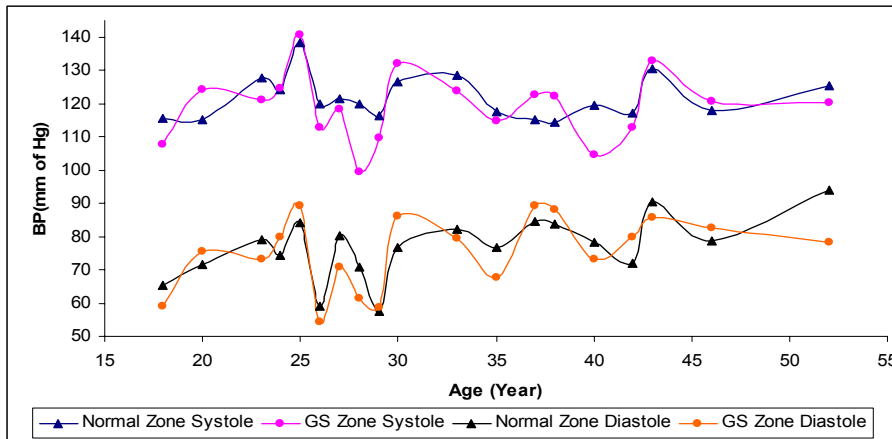

geopathic stress zone. The nature of the variation in pulse rate for different age group seems to be of

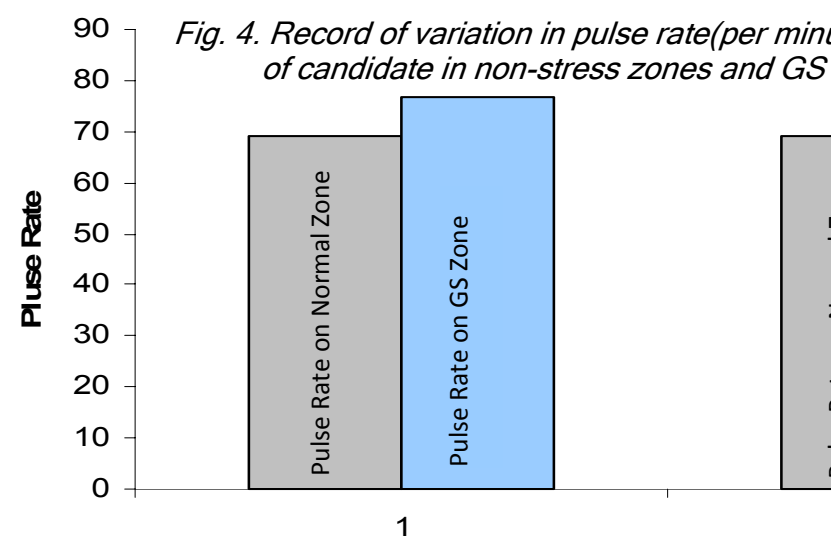

approximately same nature for both zones. Upto the age group of 25 years, pulse rate is observed to be more in normal zone in comparison to geopathic stress zone. 25 year onward the pulse rate is observed to be more in geopathic stress zone. Between the age group 30 to 40 years, similar variation with no specific pattern of increase or decrease with respect to normal and geopathic stress zone are observed. Above 45 year age, pulse rate in normal zone is found to be less than GS zone. This indicates no specific pattern / effect of geopathic stress zone on pulse rate for different age group samples, but it certainly indicates some effect of GS zone.

Fig.6 indicates that heart rate of a sample is more as well as less in GS zone in comparison to normal zone. A more detailed study is carried out further for large number of samples. Fig.7 indicates variation of heart rate w.r.t. normal on pre-identified geopathic stress zone in different age group. The nature of variation of heart rate is observed to be approximately of same nature for normal and GS zone. For most of the age group, in GS zone heart rate is found to be less in comparison to normal zone except the age group 30-35years. Although this indicates the effect of GS zone but more rigorous study may be required to reach to any concluding remark.
Vol. 3 No. 1 (Jan 2010)

ISSN: 0974- 6846
Fig. 5. Record of variation in pulse rate (per minute) of candidate in non-stress zones and GS zones vs. age of candidate.

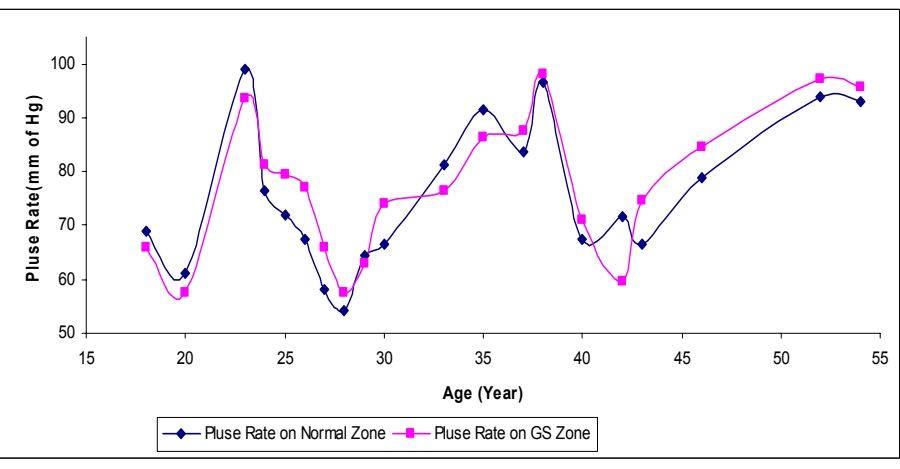

Fig. 8 indicates change in heart rate in percent Vs Age. In this case, the positive value of heart rate means HR gets increased and negative value of heart rate means HR gets decreased. It is observed that heart rate of the human vary about $10 \%$ to $15 \%$ due to geopathic stress zone in comparison to the normal zone.

\section{Conclusion}

The significant difference in the physical parameters noticed lead to the conclusion that the GS zone exerted different influence on the normal functioning of the human body especially changes in BP and HR. The common effects of GS zone observed includes feeling run-down and exhausted, depression, nervousness, headaches, tingling in arms and legs etc. depending upon age group. As a result, different retardation of immune system and other organ may occur. Though GS doesn't cause any serious illness, it can be predicted that it may lower immune system and one's ability to fight off virus and bacteria. The scientific basis of the conclusion is explored in this paper. In the present study, the candidates were exposed to GS zone for 20 minutes. However, it is felt that for

Fig. 6. Record of variation in heart rate (bpm) of candidate in non-stress zones and GS zones

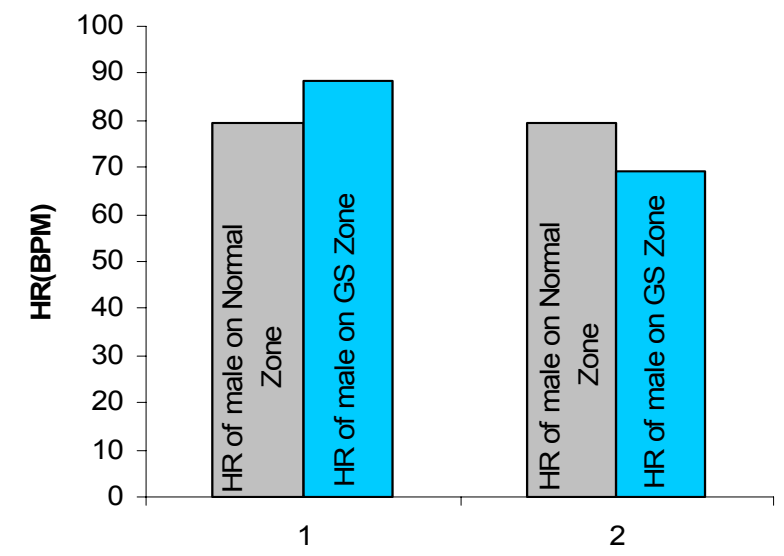

Research article

CIndian Society for Education and Environment (iSee)
Geopathic stress on human heart rate http://www.indjst.org
Dharmadhikari et al. Indian J.Sci.Technol. 
further study of effect of GS zone on people, they may be exposed for a longer duration to the GS zone say 6-8 hours(especially during sleeping period). This will also help in arriving at a better conclusion. By generating a larger data base, studies as regards establishing the corelation between the various parameters await further research.

Fig. 7. Record of variation in heart rate (bpm) of candidate in non-stress zones and GS zones vs. age of candidate

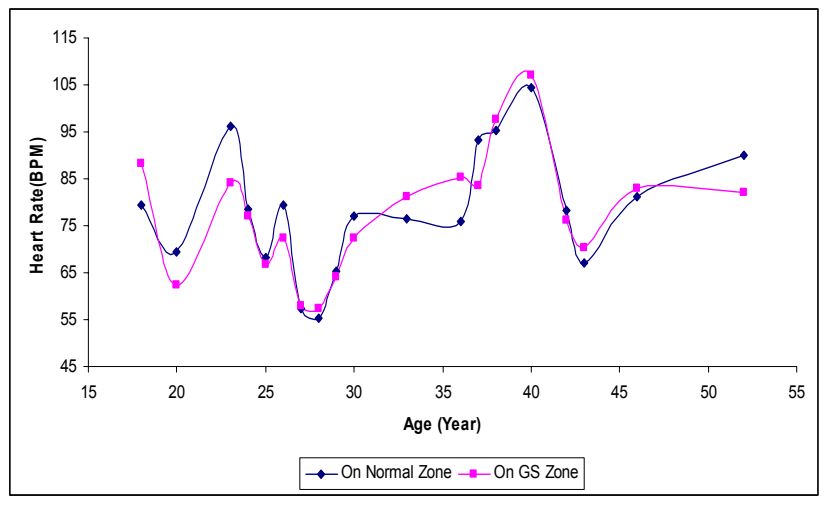

Fig. 8. Change in Heart rate in \% Vs Age

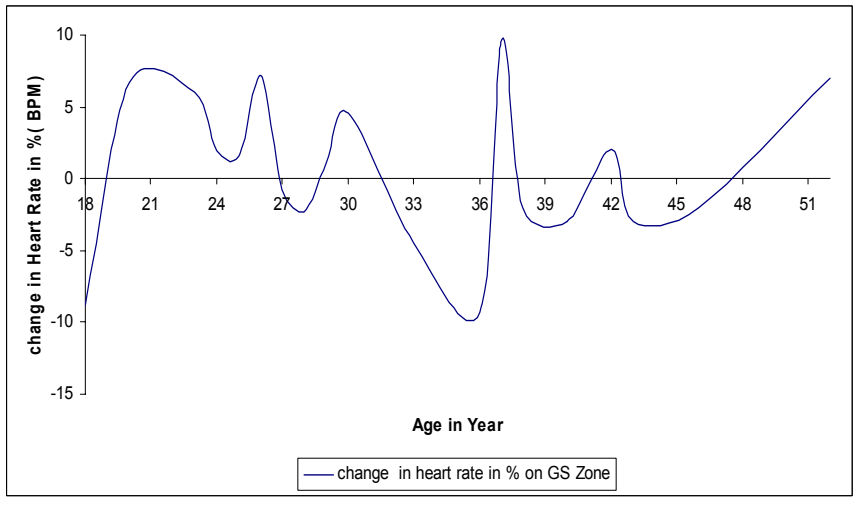

Acknowledgement

The authors (NPD and SDA) are thankful to BCUD, Univ. of Pune for providing funding to carry out the work.
4. Croome DJ (1994) The Effect of Geopathic Stress on Building Occupants, Renewable Energy, 993-996.

5. Derrickson B (2006) Principles of anatomy and physiology, $11^{\text {th }}$ Ed., Willely, ISBN:0-471-71871-8. pp:719-722.

6. Dharmadhikari NP (2009) A study of geopathic stress using light interference techniques, submitted to Curr. Sci. (R-182).

7. Dubrov AP (2008) Geopathic zones and oncological diseases. Druskininkai. 42-44.

8. Freshwater D (1997) Geopathic Stress. Complement Therapies in Nursing \& Midwifery, (3), 160-162.

9. Gordon R (2005) Are you sleeping in a safe place? Dulwich health 130 Gipsy Hill, London SE19, $7^{\text {th }}$ edition, ISBN 09514017 0X. pp:9-10.

10. Gridin VI (2008) About nature influence geophysics Earth's fields anomalies on the living systems. Druskininkai. 88-91.

11. Hacker GW (2005) Biomedical Evidence of Influence of Geopathic Zones on the Human Body: In: Scientifically Traceable Effects and Ways of Harmonization, Forsch Komplementärmed Klass Naturheilkd Karger. pp: 315-327.

12. Hacker GW (2008) Geopathic stress zone and their influences on human organism. Druskininkai. 8-27.

13. Jauchem JR (1997) Exposure to low frequency electromagnetic and radiofrequency radiation, Int. Arch. Occup. Environ. Health. 70, 9-21.

14. Kathe B (1989) Earth radiation. Word Asters Ltd., ISBN 095141510 7. pp:34.

15. Milliren TJ (1993) Noxious (Geopathic) fields are damaging to your health. Self published.

16. Pohl GF (1993) Earth currents: Causative factors of cancer and other diseases, Frech-Verlag, Stuttgart

17. Saunders T (2003) Health hazards and electromagnetic fields. Complementary Therapies in Nursing \& Midwifery, (9), 191-197.

18. Storozuk GA (2002) Geopathic Zones and The Iron Stake Method-No-2, A Dowser's Series. pp: 12-20.

19. Thurnell-Read J (2006) Geopathic Stress and Subtle Energy, Life-Work Potential, ISBN-9542439-4-3. pp: $11-24$

\section{References}

1. Betz HD (1995) Unconventional Water Detection: Field Test of the Dowsing Technique in Dry Zones, Part I \& II. J. Scientific Exploration .(9), 1- 43.

2. Bird C (1993) The divining hand. Whit Ford Press, ISBN;0553345397.

3. Bortkiewicz A and Gadzicka E (1996) Heart rate variability in workers exposed to medium frequency electromagnetic fields. J. Autonomic Nervous System, 59(3), 91-97. 